Eurasian Journal of Business and Economics, 13(26), 65-91, (2020).

\title{
Determinants of Indian Automobile Industry Growth
}

\author{
Sanchita Ghosh CHOWDHURY*, Suhita CHATTERJEE ${ }^{* *}$
}

Received: April 04, 2020 Revised: September 14, 2020 Accepted: September 18, 2020.

\begin{abstract}
The paper attempts to identify the most influencing factors determining automobile industry growth in India. The paper takes into account a 19-year time period from 1998 to 2016 for 12 firms belonging to the automobile industry in India. The SCP model is used as a framework for examining the performance of the automobile industry. Unlike, the previous studies that are mostly time-series or cross-sectional analysis, the present study employs panel data analysis to measure the impact of selected determinants on automobile industry growth. The paper finds that labour and capital productivity, promotional measures, import intensity, fixed asset turnover, net profit margin and age of the firm as significant determinants of automobile industry growth in India. Further, the findings help to justify the impact of industrial policies on the growth of the industry during this time.
\end{abstract}

Keywords: Automobile Industry, Growth, SCP Model, Panel Data, Policy, India

JEL Code Classifications: D22, L10, L62, 025

UDC: 658.274

DOI: https://doi.org/10.17015/ejbe.2020.026.04.

\footnotetext{
*Assistant Professor, Xavier Institute of Tribal Education, Jamshedpur, India. e-mail: sanchitagc@gmail.com

${ }^{* *}$ Assistant Professor, The Graduate School College for Women, Jamshedpur, India.

e-mail: suhita.chatterjee@gmail.com

Copyright (C), 2020 Ala-Too International University.
} 


\section{Introduction}

The automobile industry is one of the core industries in India. As in any other nation of the world, the key to India's development lies in a well-developed transportation system and therein lays the strategic importance of the automobile industry. Recognising automobile industry as one of the core or pillar industry to achieve economic growth the Indian government has been nurturing this industry through policy measures. With its interlinkages with other industrial sectors, the Indian automobile industry is considered as a major driver of manufacturing the gross domestic product, exports, and employment (Miglani, 2019). It is also said to be the barometer of the economy as its performance is viewed as a reflection of economic confidence (Kaul, 2016). It has, therefore, been marked as a sunrise sector in the Indian economy. However, recently the automobile industry in India has faced slowdown and 2019 marked as the worst with an abrupt decline in the sales and piling inventory. According to the Society of Indian Automobile Manufacturers (SIAM), passenger vehicle witnessed a decrease in sales by 17.98 per cent in AprilDecember 2019 over the same period last year (James, 2019). The growth of an industry is subject to many factors. The aim of this study, which is to identify the most influencing amongst them would make it useful for policymakers and economists to build up a model which can then be used to foster rapid growth in the industry and reviving it with a likely positive significant effect on the whole economy.

The period under consideration in the study is the post globalisation period which was marked by multiple events. The Liberalisation, Privatisation and Globalisation (LPG) model was implemented to induce fast growth into the economy and make the nation globally competitive. Reforms were undertaken in all sectors of the economy with an attempt to promote efficiency. The progressive and unrestrictive governance which marked this new era led the country on to a fast track to prosperity and development.

During this time, several major changes can be traced to have a positive impact on the automobile industry too! The unrestricted expansion of capacity helped the firms to take advantage of the returns to scale without getting tangled into the red tape of bureaucracy. The financial inflows from foreign firms and institutions ensured a continuous supply of capital which is so critical to the growth of an industry. The uninhibited trade with foreign countries gave the industry exposure to global demand which not only expanded the market but also gave an opening to rising standards. The mutual exchange of technology and knowledge between firms of different nations promoted much faster growth and development in the Indian automobile industry. The opening up of the economy to foreign direct investment by providing facilities to foreign companies to invest in the industry, the removing of constraints and obstacles to the entry of multinationals in India and the allowance to Indian companies to enter into foreign collaborations or to set up joint ventures in India and abroad, brought about massive positive changes in the performance of the industry. Such activities also generated a large magnitude of employment and 
helped to reduce the intensity of poverty in the nation and simultaneously increased the purchasing power of the masses. The paper attempts to empirically re-examine the impact of the selected determinants on the growth of the automobile industry in India.

The study is divided into seven sections: Section 2 gives a review of literature, section 3 provides an overview of SCP in the Indian automobile industry and deals with the analytical framework of the study and specifies the model, section 4 discusses the measurement of growth and analyses the possible impact of the predictor variables (determinants), section 5 describes the estimation techniques applied, section 6 presents and discusses the empirical findings and section 7 concludes.

\section{Review of Literature}

Before this study, various studies have empirically measured the impact of various determinants on automobile industry growth. A few such studies are, Narayanan (1998), Dasgupta (1986), Corvers (1997), Narayanan (2001), Chaudhuri et al. (2010), Saripalle (2012), Rao (1993), Mukherjee and Sastry (1996), Kim and McElreath (2001), Garg and Singh (2005), Lee and Anderson (2006), Richet and Ruet (2008), Badri Narayanan and Vashisht (2008), Burange and Yamini (2008), Carlos et al. (2009), Vikkraman and Varadharajan (2009), Das and Das (2012), Ray (2012) and Menon and Raj (2012). However, some of the studies like Corvers (1997), Mukherjee and Sastry (1996), Lee and Anderson (2006) and Carlos et al. (2009) are global studies, whereas, the studies by Richet and Ruet (2008), Menon and Raj (2012) and Chattopadhyay (2013) are based on just one segment of the industry or is a survey based on a particular state or locality. Further, the firm-level studies of empirical nature include Narayanan (1998), Narayanan (2001), Chaudhuri et al. (2010), Saripalle (2012), Badri Narayanan and Vashisht (2008), Das and Das (2012), and Ray (2012). Moreover, most of these studies analyse the impact of a few determinants over a period. Such determinants are generally indicative of a particular factor. For example, Narayanan (1998) and Badri Narayanan and Vashisht (2008) study competitiveness whereas, Saripalle (2012) studies the impact of knowledge assimilation. Ray (2012) studies the effect of capacity utilisation, whereas Das and Das (2012) study the impact of R\&D only. Chaudhuri et al. (2010) study the variations in firm-level investment growth in three industries, namely, auto components, chemicals, and electronics. Further, the studies by Dasgupta (1986), Rao (1993), Kim and McElreath (2001), Burange and Yamini (2008) and Vikkraman and Varadharajan (2009) analyse the growth of the industry over a very short period. Unlike, the previous studies that are mostly time-series or cross-sectional analysis, the present study is an attempt towards capturing the determinants significantly influencing automobile sector growth in India under the panel data analysis.

A discussion of the available research points towards the limited availability of an empirical study that covers a long period that has seen multiple changes in the economic and policy environment that industry is exposed to. Also required, is a 
study that analyses multiple determinants across the period, to compare their relative importance. This paper aims at a firm-level study of the impact of multiple determinants on automobile industry growth across the period of 1998 to 2016 . The findings also help to justify the impact of industrial policies on the growth of the industry during this time.

\section{SCP in the Automobile Industry in India: An Overview}

The SCP model provides a framework, which defines the structure, conduct and performance of the firms and helps to analyse the way in which the structure of the industry impacts the performance of the firms through their conduct. The studies of Nag et al. (2007) and Kumar and Kaur (2014) have examined the automobile industry in the framework of the Structure-Conduct-Performance (SCP) model. Nag et al. (2007) examine the growth patterns, changes in ownership structures, trade patterns and role of governments in the automobile sector of China, India, Indonesia, and Thailand. Kumar and Kaur (2014) use the structure conduct performance paradigm to study the market concentration in the Indian automobile industry. Other studies, like Edwards et al. (2006) and Sahoo and Mishra (2012), have explored other sectors within the same framework. However, in the case of the automobile industry in India, this paradigm is not much explored.

The SCP paradigm proposes that the market structure determines the conduct of firms in an industry, which in turn determines their performance. The structure of the market is determined by the nature of the product, the market concentration, product differentiation and the existing barriers to enter the market. The conduct of the market reflects buyer and seller behaviour, including the strategic behaviour of the firms and their investment for growth. The performance of the firms is measured by comparing the financial performance of firms along with the industry in terms of productivity, efficiency terms and profitability levels.

The present study, therefore, attempts to explore the impact of industrial policies on the growth of the automobile industry in the context of the multidirectional and dynamic SCP framework. The study hypothesises that industrial policies impact the structure, conduct and performance of the firms in an industry.

\subsection{The Structure of the Market}

The structure of a market is the set of conditions and characteristics that describe and define the market type. The automobile market in India is oligopolistic in nature. The top 40 per cent of firms account for more than 94 per cent of the total market share. The market thrives on product differentiation, and much of the competition is, therefore, non-price competition. Additionally, the high costs of advertisements act as barriers to entry for new firms. Another barrier to entry is the high technology environment of the industry, which makes research and development a necessity for all firms, thus increasing investment costs hugely. The present study uses the size of firms and their market share as indicators of the structure of the market. Location 
and ownership indicators, which indicate regional clustering and joint ventures are also considered to be indicators of the structure of the market. It is noticed that the market shares of the firms have changed over the years. The market share has decreased for some firms and increased for the others. New firms have come into the market, which has led to a dilution in market share. Alternatively, mergers and acquisitions in the market have led to an increase in the market share of others. The median market shares and the standard deviation in the market share of the selected firms over the years are summarised in Table 1. Further, the Herfindahl Index (H.I.), also shown in Table 1, indicates the concentration of the market. The Herfindahl Index is the sum of the squares of the relative sizes (i.e. market shares) of the firms in the market, where the relative sizes are expressed as proportions of the total size of the market (Barthwal, 2010).

$$
\text { Herfindahl Index }=\sum_{i}^{n}\left(P_{i}{ }^{2}\right)
$$

Where $\mathrm{Pi}=\mathrm{qi} / \mathrm{Q}$, qi is the output of the firm and $\mathrm{Q}$ is the total output of all the firms in the market, and $\mathrm{n}$ is the total number of firms. The maximum value for the index is one where only one firm occupies the whole market. This is the case of a monopoly. The index will have minimum value when the $\mathrm{n}$ firms in the market hold an identical share.

\section{Table 1. Structure of the Automobile Industry in India}

\begin{tabular}{lccc}
\hline Year & Median Market Share & Standard Deviation & HI \\
\hline 1998 & 3.72 & 12.74 & 0.26 \\
\hline 1999 & 4.08 & 11.64 & 0.23 \\
\hline 2000 & 3.92 & 11.13 & 0.22 \\
\hline 2001 & 4.09 & 10.15 & 0.20 \\
\hline 2002 & 4.31 & 9.80 & 0.19 \\
\hline 2003 & 5.47 & 9.21 & 0.18 \\
\hline 2004 & 4.78 & 9.54 & 0.18 \\
\hline 2005 & 4.38 & 9.95 & 0.19 \\
\hline 2006 & 3.89 & 10.16 & 0.20 \\
\hline 2007 & 3.81 & 10.64 & 0.21 \\
\hline 2008 & 3.24 & 10.63 & 0.21 \\
\hline 2009 & 2.51 & 10.50 & 0.20 \\
\hline 2010 & 2.32 & 10.92 & 0.21 \\
\hline 2011 & 2.74 & 11.00 & 0.22 \\
\hline 2012 & 2.88 & 10.87 & 0.21 \\
\hline 2013 & 2.82 & 10.45 & 0.20 \\
\hline 2014 & 3.28 & 10.18 & 0.20 \\
\hline 2015 & 3.77 & 9.88 & 0.19 \\
\hline 2016 & 4.30 & 9.63 & 0.19 \\
\hline
\end{tabular}

Note: Median Market Share is in percentages; Standard Deviation is in absolute numbers 
Table 1 clearly shows the changing structure of the industry. The median market share is rising, whereas the deviation and market concentration, as shown by H.I., is falling. Therefore, from the leadership form of oligopoly, the market is slowly shifting to the contestable market model. To investigate the various reasons for such change to have occurred, the conduct and performance of the market need to be analysed.

\subsection{The Conduct of the Market}

When the market is imperfect, a firm needs to employ competitive strategies in order to capture more and more market share. One way of doing it is to differentiate the product in the minds of the consumer by using promotional strategies like advertising and marketing. Advertising provides the consumer with information about the product or service, its functional aspects, and its utility over others of its kind and then nurtures and develops the emotion in a consumer which leads to final buying behaviour. In the process, the firm is able to generate for itself a certain level of initial trust in the consumer which the product must then hold up. A successful advertising strategy generates good financial performance by enhancing the image of the firm and at the same time helping it to capture market share from its rivals and creating barriers to entry for other firms in the market. However, in certain cases, counter-advertising by rivals wipe out the positive profits gained through advertising, thus resulting in a sort of 'zero-sum game' or may also result in declining profits. Marketing, on the other hand, includes advertising and much more. It is a combination of business activities, including systematic planning and implementation in order to build effective communication between buyers and sellers for mutual advantage. Although advertising is a big part of marketing, there are other components to marketing like market research, media planning, public relations, product pricing, distribution, customer support, sales strategy, and community involvement. A good marketing effort leads to correct forecasting of demand as well as proper pricing of the product, which finally leads to profitability for the firm. Improper marketing, on the other hand, may have a negative impact on both image and performance of the firm.

Another way in which firms tend to compete and gain market share is through 'research and development' (R\&D). R\&D can lead to multiple advantages. It increases the possibility of improved productivity or new product lines, giving the firm a definite competitive advantage. If R\&D efforts result in a process invention, it helps to decrease marginal costs or increasing marginal productivity and thereby helps the firm to realise a competitive advantage over other firms. In both ways, successful $R \& D$ will help to improve firm financial performance. However, the effect of R\&D is not instantaneous. It comes with a variable time lag and a risk of failure attached to it. The initial investment required for proper research and development initiatives is quite substantial, while the returns are slow and indefinite. Therefore, the present study assumes that the firms which are able to invest a sufficient amount of capital in research and development initiatives are more likely to gain higher market share over the others. 
In the present study, two measures of firm conduct are considered. The 'Promotional Intensity' (the total of marketing and advertising expenses as a ratio of sales) measures the selling efforts of the firm, while the 'R\&D Intensity' (R\&D expenses as a percentage of sales) measures the development initiatives of the firm. Table 2 gives an account of the market conduct of the automobile industry over the years 1998 to 2016.

\section{Table 2. Market Conduct of the Automobile Industry over the Years}

\begin{tabular}{lcc}
\hline Year & Promotional Intensity & Research and Development Intensity \\
\hline 1998 & 0.86 & 0.84 \\
\hline 1999 & 0.87 & 0.66 \\
\hline 2000 & 0.04 & 0.55 \\
\hline 2001 & 0.04 & 0.49 \\
\hline 2002 & 0.04 & 0.56 \\
\hline 2003 & 0.05 & 0.50 \\
\hline 2004 & 0.04 & 0.57 \\
\hline 2005 & 0.05 & 0.47 \\
\hline 2006 & 0.04 & 0.44 \\
\hline 2007 & 0.04 & 0.47 \\
\hline 2008 & 0.03 & 0.46 \\
\hline 2009 & 0.03 & 0.39 \\
\hline 2010 & 0.04 & 0.38 \\
\hline 2011 & 0.03 & 1.00 \\
\hline 2012 & 0.03 & 1.19 \\
\hline 2013 & 0.03 & 1.33 \\
\hline 2014 & 0.03 & 1.67 \\
\hline 2015 & 0.03 & 0.78 \\
\hline 2016 & 0.03 & 0.80 \\
\hline
\end{tabular}

All figures are in percentages

Table 2 shows that where there is a clear decrease in promotional intensity over the years. This is mainly because although expenses on advertising and marketing have increased, they have not kept up the same pace as the increase in sales. This led to a fall in the ratio over the years. The research and development intensity, on the other hand, has been cyclical in nature. It clearly signifies the importance of the fact that the investment on research and development takes time to yield returns and that the firm may not actually invest an increasing amount of capital on research and development each financial year. A cyclical pattern can be noticed in case of R\&D Intensity that signifies intermittent periods of increased R\&D spending, which is most likely to have been influenced by external factors like industrial policies.

\subsection{Performance of the Firms}

The performance of a firm may be measured in various ways. The most common measure of performance is the firm's profits. If the profits of a firm are continually increasing, it is taken to be a dependable indicator of growth. On the other hand, a 
fall in profits over long periods indicates financial stress in the firm and maybe deterrent to its growth. Another way to judge firm performance is to judge the firm's increase in productivity. Increase in the overall productivity of the firm is indicative of efficiency. Increase in labour productivity indicates the use of specialised manpower and returns on investment in training and development of employees. Increase in capital productivity implies that there is process improvement leading to more sales per unit of capital.

In the present study, the measures used to indicate the performance of firms are multiple. They can be divided into two categories. The first category is productivity which is measured with several indicators. 'Labour' and 'capital' productivity measures the sales per unit of labour and capital respectively, 'capital efficiency' measures the sales per unit of capital employed, 'capital intensity' measures the change in capital-labour ratio and 'fixed asset turnover' measures the change in the efficiency of fixed assets. The second category is profitability which is also measured with the help of several indicators. 'Knowledge outsourcing intensity' and 'import intensity' measures the pace of technological advancement of the firm while the 'net profit margin' measures the level of business profits of the firm. Table 3 shows the overall performance of the firms regarding these indicators.

Table 3 gives a clear picture of the performance of the industry with respect to the performance indicator determinants. It is seen that overall productivity along with labour productivity, knowledge outsourcing intensity, capital efficiency and fixed asset turnover has increased so marginally over the 19 years that they may be considered to be almost stagnant. This implies that the increase in those expenditures has kept almost the same pace with the increase in sales of the firm. On the other hand, capital productivity, promotional intensity, import intensity and net profit margin has shown a decline over the years under study. This implies that over the years, expenditure on advertising, marketing and imports have not kept the same pace as the increase in sales. The decline in capital productivity and net profit margin reflects the rising investment in long term capital and projects, which requires a considerable number of years to break even. However, this is only natural when an industry is engaged in a fast pace of innovation, as is with the automobile industry in India. 
Determinants of Indian Automobile Industry Growth

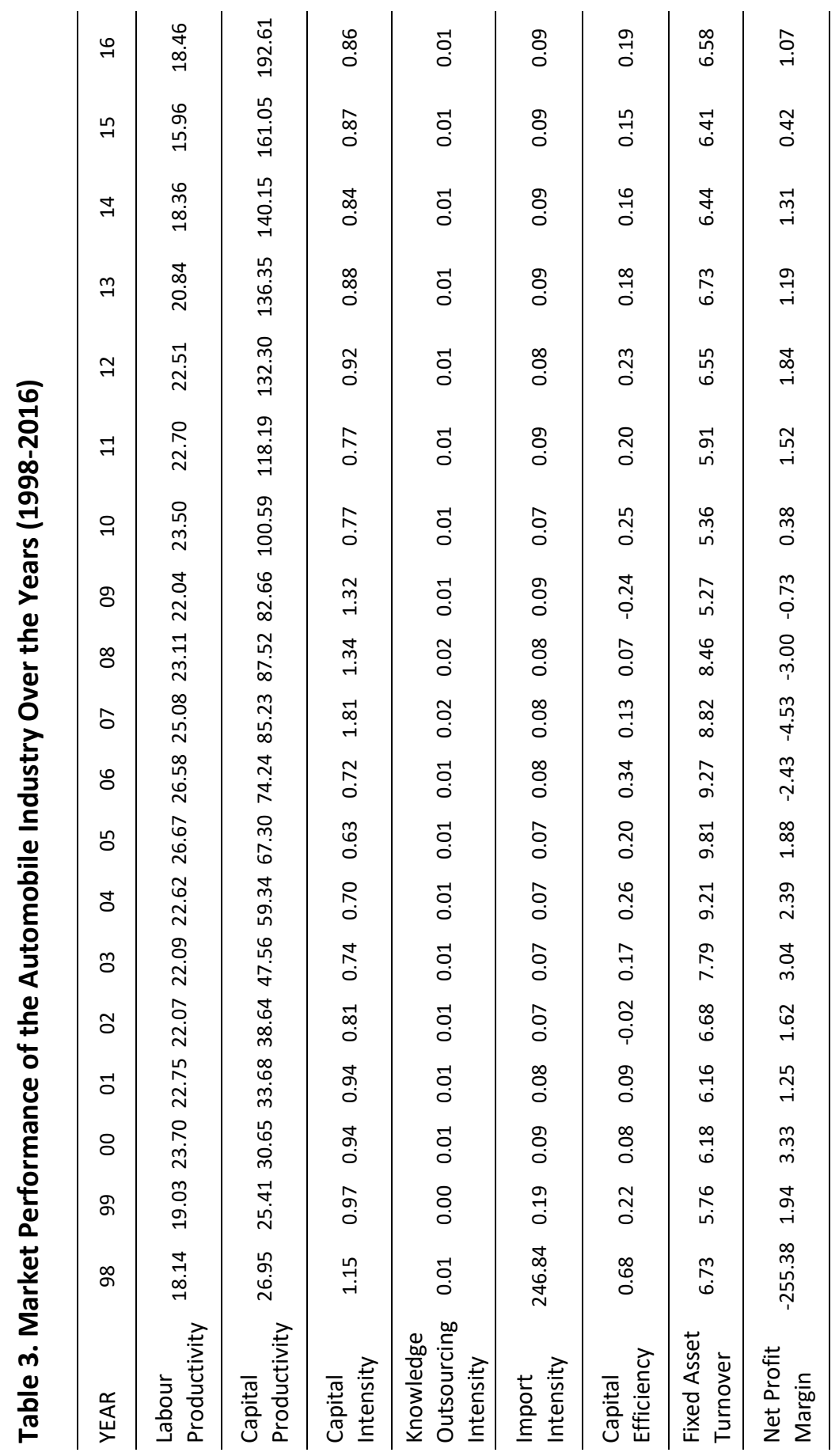




\subsection{SCP Relationships in Indian Automobile Industry: Model Specification}

In the present study, the SCP hypothesis has been examined using the growth of the automobile industry in India as an indicator of performance. This can be represented with the following functional relationship.

Growth $_{\text {Auto }}=Y_{i}=f\left(X_{i}, Z_{i}\right)$

Where $Y_{i}$ represents the growth of the ith firm.

$X_{i}$ is the set of SCP variables of the ith firm, and $Z_{i}$ are other associated variables of ith firm.

$X_{i}=\varnothing\left(M S_{i}, P_{R O M}, R_{i} D_{i}, \operatorname{LPROD}_{i}, \mathrm{CPROD}_{i}, \mathrm{CE}_{i}, \mathrm{CI}_{i}, \mathrm{FAT}_{i}, \mathrm{KOI}_{i}, \mathrm{IMI}_{i}, N P M_{i}\right)$

Here, $\mathrm{MS}_{\mathrm{i}}$ stands for the Market share of the firm, $\mathrm{PROM}$ is the promotional intensity of the firm, RNDi is research and development intensity of the firm with a one year lag, $L P R O D_{i}$ is the sales per unit of labour of the firm with a one year lag, CPROD is the capital per unit of labour of the firm with a one year lag, $\mathrm{CE}_{\mathrm{i}}$ is the change in capital employed of the firm, $\mathrm{Cl}_{i}$ is the capital intensity representing the capitallabour ratio of the firm, $\mathrm{FAT}_{\mathrm{i}}$ is the fixed asset turnover of the firm with a one year $\mathrm{lag}, \mathrm{KOI}_{i}$ is the knowledge outsourcing intensity of the firm with a one year lag, IMI is the import intensity of the firm, and $N P M_{i}$ is the net profit margin of the firm.

Apart from the above-mentioned variables, the study considers some other variables as a part of the empirical analysis. The impact of the SCP variables on automobile industry growth can be correctly measured only by controlling the impact of certain other variables. In that light, the study considers 'Age of the firm' (measured as the natural log of the number of years since incorporation) as a control variable. The study also considers two dummy variables, 'location' and 'ownership' to isolate the impact of a firm's location and ownership on its growth. The 'location' dummy isolates the impact of being situated in one of the three major automobile clusters in India whereas the 'ownership' dummy isolates the impact of being a foreign company or a joint venture.

$Z_{i}=\varphi\left(A G E_{i}, L O C_{i}, O W N_{i}\right)$

Here, AGE is the age of the firm, measured as the difference between the year 2016 and its year of incorporation, LOC is a dummy representing 1 if the firm is located in one of the 3 clusters or 0 otherwise, OWN is a dummy which takes value 0 if the firm is a joint venture with multinational or foreign-owned and 1 if Indian.

Substituting (2) \& (3) in (1),

$Y_{i t}=f\left[\varnothing\left(M S_{i}, P R O M_{i}, R N D_{i}, L P R O D_{i}, C P R O D_{i}, C E_{i}, C I_{i}, F A T_{i}, K O I_{i}\right.\right.$,

$\left.\left.I M I_{i}, N P M_{i}\right), \varphi\left(A G E_{i}, L O C_{i}, O W N_{i}\right)\right]$

As the influence of the factors on firm's growth may not be instantaneous, and many of the independent variables may be influenced by firm's growth as well, the present study introduces a lag of one year for the performance components (except C.E., Cl, 
FAT, IMI and NPM) to capture the dynamics of adjustments as well as to control for the problem of endogeneity. The functional relationship (4) is, therefore, reduced to $Y_{i t}=f\left[\varnothing\left(M S_{i, t}, P_{R O M_{i, t}}, R N D_{i, t-1}, L P R O D_{i, t-1}, C P R O D_{i, t-1}, C E_{i, t}, C I_{i, t}, F A T_{i, t-1}, K_{i, t-1}\right.\right.$, $\left.\left.I M I_{i, t}, N P M_{i, t}\right), \varphi\left(A G E_{i, t}, L O C_{i, t}, O W N_{i, t}\right)\right]$

Assuming that there exists linearity in the relationships, the above functional relationship can be rewritten as

$Y_{i t}=\alpha+\beta_{1} M S_{i, t}+\beta_{2} P_{R O M_{i, t}}+\beta_{3} R N D_{i, t-1}+\beta_{4} L P R O D_{i, t-1}+\beta_{5} C P R O D_{i, t-1}+$ $\beta_{6} C E_{i, t}+\beta_{7} C I_{i, t}+\beta_{8} F A T_{i, t-1}+\beta_{9} K O I_{i, t-1}+\beta_{10} I M I_{i, t}+\beta_{11} N P M_{i, t}+\beta_{12} A G E_{i, t}+$ $\beta_{13} L O C_{i, t}+\beta_{14} O W N_{i, t}+\mu_{i t}$

Here, $\mathrm{u}_{\mathrm{it}}$ stands for the random disturbance term.

$\alpha$ is the intercept, $\beta_{j}$ represents the coefficient $j, j=1,2, \ldots \ldots, 14$ for the indicators for firm $i, i=1,2, \ldots \ldots ., 12$ over the period $t, t=1,2, \ldots . ., 19$

From (6) it appears that the growth of the automobile industry is determined by the determinants, which impact the structure, conduct and performance of the automobile industry in India.

\section{The Measurement of Growth and Possible Impact of the Explanatory Variables}

\subsection{The Measurement of Growth}

The rise in sales in a firm indicates its growth. Various studies have measured growth in various ways. Buzzell et al. (1975) use an increase in market share as an indicator of growth, whereas Peterson and Ahmed (2007) consider the 'Birch Index' as a proxy for growth. However, following the study of Mogos et al. (2015), the present study measures growth by taking the differences between the natural logarithm of sales in year $t$ and year $\mathrm{t}-1$.

\subsection{Possible Impact of the Explanatory Variables}

Market Share: Market share, measured as a ratio of firm sales to industry sales, is expected to have a negative relationship to the firm's growth. This is because, in an oligopolistic setting where the market is contestable and the industry is in the pioneering stage of growth, the industry sales grow at a faster pace than the firm sales. Hence, the growth of the firm will not necessarily lead to an increased market share always, rather for large firms it is more likely to decrease.

Promotional Intensity: Promotional intensity is measured as a ratio of the firm's promotional expenses to its sales. The promotional expense incurred by a firm is a sum of its advertising and marketing expenses. Mukherjee (2000), Burange and Yamini (2008) and Narayanan (2001) have documented increased promotional expenditures of firms over the years, making it one of the major indicators of competitiveness. Barthwal (2010) finds advertising to be more relevant in 
concentrated or oligopolistic markets where few large firms dominate the market. It considers advertising as a form of non-price competition that does not lead to price competition rather aim at creating product differentiation and modifying the consumer's perception of the product. Similarly, according to Narayanan (2001)4, in the post globalisation period, the entry of multinationals in the automobile industry gave way to non-price competitions in which advertisements played a major role. However, though the promotional expenses of the firms have grown over the years, it has certainly not grown at the same pace as sales. Hence, the percentage of sales spent on promotional expenses has declined steadily for most of the firms. Therefore, the growth of the firm has seen a decline in the promotional intensity, although there has been a steady rise in the promotional expenses. Thus, the promotional intensity is expected to have a negative relationship with growth.

Lagged Research and Development Intensity: The variable is measured as the ratio of research and development expenses and total sales. Since the impact of research and development efforts is not instantaneous; an once year lag has been included. Past research lack consensus regarding the impact of this variable on growth, thus meriting a further interest in the variable. Piplai (2001), Richet and Ruet (2008) and Rao (1993) find that research and development promote growth. Similarly, Dogan et al. (2016) find research and development to have a significant positive impact on the performance of Turkish manufacturing industry firms. However, Narayanan and Vashisht (2008) find that the intensity of research and development has declined over time with growth in the industry. Further, Narayanan (2001) and Nauhria, Pandey and Kulkarni (2011) find no significant relationship between research and development and growth of the automobile industry in India. The research and development initiatives have picked up pace in the Indian automobile industry only post 2005, and even then, it is still slow. Such expenses, although rising each year, are still a very small part of the total expenses. Therefore, the determinant is expected to have a weak negative relationship with growth.

Lagged Labour Productivity: Researchers fail to agree on the impact of this indicator on the growth of the automobile industry in India. Mudkanna and Losarwar (2014) and Corvers (1997) find a positive impact of employee potential on the success of a firm whereas, Narayanan (1998) concludes that the relationship between skill intensity and the growth of a firm is negative. However, the studies differ widely with respect to the period and factors under consideration. This necessitates for an analysis of the impact of this indicator on the growth of the automobile industry in India for a longer period. It is then noticed that, with specialisation setting in across the industry, firms are making an effort to train their employees with specific requirements of skill development. The era of temporary workers is gradually making the pathway for permanency of a trained and skilled workforce. However, a considerable amount of money spent on training and development as well as higher compensation to the trained and permanent workforce is the reason behind rising labour costs in the industry. In the present study, this indicator, which is measured as the sales per unit of labour employed, is therefore expected to vary negatively 
with growth. Taking into consideration the fact that increase in labour productivity induced through skill training and other development programs take at least a year to impact the growth of the firm, a once year lag has been taken for analysis.

Lagged Capital Productivity: Many studies including those of Kathuria (1987), Narayanan (1998), Narayanan (2001), Piplai (2001), Richet, Ruet (2008), Lieberman and Kang (2008), Ranawat and Tiwari (2009), Chaudhuri, Koudal and Seshadri (2010), Nag (2011) and Bhasker (2013) have found a positive relationship between capital productivity and growth of the automobile industry in India. However, most of these studies had been carried out over shorter durations of time and reflected the shortterm productivity of capital. In the present study, capital productivity is measured as a ratio of total sales to total capital and this indicator is expected to have a significant relationship with growth. This is because the industry being in the pioneering stage is investing a huge amount of capital, in the form of costs of plant and machinery that are supposed to lead to a growth in the sales per unit of capital. However, there is a slight possibility of a weak negative relationship as growth itself has been negative over a few of the years under consideration. A lag of one year has been taken to accommodate the fact that capital investment may not give instant returns.

Capital Efficiency: Past studies are not unanimous in their conclusion about the impact of capital efficiency on growth. Ranawat and Tiwari (2009) find a positive relationship, whereas Narayanan and Vashisht (2008) finds that capital efficiency has fallen over time in the unorganised automobile sector in India. Narayanan (2001) does not find capital intensity to be an important discriminatory factor in the behaviour of firms in his study. Hence, the exact nature of the impact of capital efficiency on growth is largely an empirical question. However, it can be hypothesised that the capital-intensive nature of the industry aims at increasing the amount of capital employed each year, which may be one of the factors contributing to the growth of the firm. The reverse also may hold true, that is, growth of the industry attracts more and more capital to the industry. Again, when capital employed falls, the growth also takes a downward turn. In the present study, capital efficiency is measured as the change in capital employed and is expected to vary positively with growth.

Capital Intensity: This ratio measures the capital-intensive nature of the industry and is the ratio of capital to labour. As the nature of the industry suggests, this ratio is expected to have a positive relationship with growth. With skill development setting in together with the mechanisation of production processes, the number of labourers employed has come down in comparison to the capital employed and hence the ratio has increased with a rise in growth.

Lagged Fixed Asset Turnover: This is measured as the ratio of sales to net fixed assets. An increase in net fixed assets over the years to increase the capital base of the industry justifies the fact that this indicator will possibly vary negatively with growth. Almost all the firms in this industry are expanding, whether by capacity or by vertical integration. This requires much spending on fixed assets and hence the 
negative relationship between growth and the fixed asset turnover ratio. This variable has also been induced with a lag of one year as fixed assets may give delayed returns.

Lagged Knowledge Outsourcing Intensity: Although quite a few studies like Narayanan (1998), Piplai (2001), Saripalle (2012), Nag (2011), Bhasker (2013), Lall (2003), Richet and Ruet (2008) and Chadha and Kapoor (2010) have mentioned the importance of outsourcing knowledge as a way of promoting growth in the automobile industry in India, quantitatively, the indicator remains sufficiently unexplored. The automobile industry in India is still developing technologically wherefore firms still require to heavily outsource technical know-how in order to increase their knowledge base, which is a primary requirement for growth. Therefore, it is most likely that this ratio, measured as the cost of outsourced knowledge over sales, will vary positively with the growth of the firm and industry. Since knowledge takes time to percolate and only then starts giving returns, therefore a lag of one year has been taken for this variable.

Lagged Import Intensity: Many studies like Narayanan (1998), Narayanan (2001), Piplai (2001), Saripalle (2012), Humphrey and Memedovic (2003), Lall (2003) and Rao (1993) have observed that the automobile manufacturers have still not achieved selfsufficiency when it comes to production processes or component manufacturing. Therefore, firms in the industry rely heavily on imports. The import intensity ratio measured as the cost of imports over sales, therefore naturally varies positively with growth. Import of technology or engineered components generally take time to be integrated into the production process and therefore a time lag has been included in the determinant.

Net Profit Margin: This ratio indicates the profitability of the company. Higher profitability of the existing enterprises in a region indicates a better business environment and hence encourages potential investors to invest therein. It also raises the ability and willingness of the existing enterprises to expand their business. Yilmaz and Acar (2018) consider the net profit margin as one of the measures of the financial performance of companies. Profitability not only represents factors like size of the firms, as shown by Hall and Weiss (1967) and Samuels and Smith (1968) or market concentration as evidenced by Bain (1951), Schwartzman (1959) and Mishra (2008) or market share as shown by Gale (1972), but also past profitability and growth as verified by Singh and Whittington (1968) and Barthwal (1977) that influence investor's perception on market performance. Therefore, it is expected to have a positive relationship with growth; however, in the backdrop of rising expenses, growth may not always be indicative of rising profits. In fact, growth, together with increased expenses, may lead to a fall in profits over time leading to a negative relationship between net profit margin and growth of the firm. 


\subsection{Possible Impact of the Control Variable}

Age: As the firm ages, it tends to become more efficient. However, if the industry is continuously facing technology and innovation shocks, only those firms that are able to adapt and keep up with the change will be able to grow. Hence, the impact of the age may vary both positively or negatively, depending on the adaptability of the firm on the changing demand and technology requirements in the industry.

\subsection{Possible Impact of the Dummy Variables}

Location: This dummy variable is expected to vary positively with the industry's growth. Presence of the firm in one of the clusters gives it easy access to components and other associated services at a comparatively lower cost than those firms, which do not have manufacturing facilities in the cluster.

Ownership: This second dummy is also can be expected to demonstrate a variable relationship with growth depending on the policy regimes. Policies favourable to foreign companies and joint ventures will give a negative relationship, whereas policies favouring Indian firms will turn the relationship into a negative one.

\section{Estimation Techniques and Data Sources}

A total of 12 firms belonging to different segments of the automobile industry in India were selected for the purpose of empirical analysis. These firms were selected based on several criteria. Firstly, these firms constitute almost 75 per cent of the total market. Secondly, the selected sample covers all the different segments that are two-wheelers, three-wheelers, passenger cars and commercial vehicles. Finally, the period under analysis, that is 1998 to 2016, naturally excludes a few of the larger firms like Bajaj Auto, Mahindra Vehicles, Volkswagen India, India Yamaha, and Daimler India, all of which were incorporated in 2007. Other firms like Honda Cars India, Skoda Auto India and Mercedes-Benz India had to be omitted due to unavailability of complete data.

A panel data analysis is used to estimate equation (6), which measures the impact of the selected determinants on automobile industry growth. The selected panel is a strongly balanced panel data set consisting of data across 12 firms over 19 years ranging from 1998 to 2016 (with one-year lags in case of certain determinants). The panel data estimation technique helps in raising the number of observations and hence the degrees of freedom. This, in turn, makes the estimators considerably efficient.

The analysis begins by estimating a random effect model (REM). The firms under analysis belong to different segments of the industry, differ in their period of operation, and have different market shares. Therefore, an inter-firm difference, as well as a temporal effect on growth, is assumed, and hence a REM is estimated. A fixed-effect model (FEM) cannot be estimated, as then the model would omit the 
time-invariant determinants, 'Location' and 'Ownership'. Therefore, equation (6) is estimated as the REM, giving us equation (7)

$$
\begin{aligned}
& Y_{i t}=\beta_{1 i}+\beta_{2} M S_{i, t}+\beta_{3} P R O M_{i, t}+\beta_{4} R N D_{i, t-1}+\beta_{5} L P R O D_{i, t-1}+\beta_{6} C P R O D_{i, t-1}+ \\
& \beta_{7} C E_{i, t}+\beta_{8} C I_{i, t}+\beta_{9} F A T_{i, t-1}+\beta_{10} \text { KOI }_{i, t-1}+\beta_{11} I M I_{i, t}+\beta_{12} N P M_{i, t}+\beta_{13} A G E_{i, t}+ \\
& \beta_{14} L O C_{i, t}+\beta_{15} O W N_{i, t}+\mu_{i t}
\end{aligned}
$$

Where $Y_{i t}$ represents the growth of the firm $i$ in year $t$

$\beta_{\mathrm{j}}$ represents the coefficient $\mathrm{j}, \mathrm{j}=2,3, \ldots \ldots, 15$ for the indicators for firm $\mathrm{i}, \mathrm{i}=1,2, \ldots \ldots, 12$ over the period $t, t=1,2, \ldots . ., 19$

and, the intercept $\beta_{1 \mathrm{i}}$ is a random variable, where,

$\beta_{1 i}=\beta_{1}+\varepsilon_{1}$

The common mean value of the intercept is $\beta_{1}$ which is the population mean, and the firm-specific intercepts differ from the population mean by the error term $\varepsilon_{i}$. This assumption justifies the fact that as the firms belong to different segments of the industry and are different in terms of their maturity and size, the impact of any individual firm characteristic on the growth is mostly random in nature and such difference brings in heterogeneity, resulting in the random nature of individual effects. It is rather the characteristics of the population from which the sample is drawn, which helps to infer.

Substituting (8) in (7),

$Y_{i t}=\beta_{1}+\beta_{2} M S_{i, t}+\beta_{3} P R O M_{i, t}+\beta_{4} R N D_{i, t-1}+\beta_{5} L P R O D_{i, t-1}+\beta_{6} C P R O D_{i, t-1}+$ $\beta_{7} C E_{i, t}+\beta_{8} C I_{i, t}+\beta_{9} F A T_{i, t-1}+\beta_{10} K O I_{i, t-1}+\beta_{11} I M I_{i, t}+\beta_{12} N P M_{i, t}+\beta_{13} A G E_{i, t}+$ $\beta_{14} L O C_{i, t}+\beta_{15} O W N_{i, t}+w_{i t}$

Where, $w_{i t}=\mu_{i t}+\epsilon_{i}$

It is assumed that the errors follow normal distribution with zero mean and constant variance, i.e, $\epsilon_{i} \sim N\left(0, \sigma_{\varepsilon}^{2}\right)$ and $\mu_{i t} \sim N\left(0, \sigma_{\mu}^{2}\right)$. It is also assumed that the individual error components are not correlated with each other, that is, $E\left(€_{t}, \mu_{j t}\right)=E\left(€_{i}, €_{j}\right)=$ $0(i \neq j)$ and are not auto correlated across both cross section and time series units, that is,

$E\left(\mu_{i t}, \mu_{t s}\right)=E\left(\mu_{i t}, \mu_{j t}\right)=E\left(\mu_{i t}, \mu_{j s}\right)=0(i \neq j ; t \neq s)$.

Therefore, $E\left(w_{i t}\right)=0$ and $\operatorname{Var}\left(w_{i t}\right)=\sigma_{\epsilon}^{2}+\sigma_{\mu}^{2}$

Equation (9) is estimated using the feasible generalised least square method (FGLS). The FGLS method of estimation returns efficient estimators even in the case when the error terms of a given cross-sectional unit at two different time points are correlated, and the value of this correlation remains same at two differently distinct points of time. Similarly, the correlation coefficient may also remain the same across individual units. 
Even though the FEM omits the time-invariant dummy variables in the model, still, in order to substantiate the findings, the FEM is also estimated, and its suitability against the REM is tested. The FEM assumes that the slope coefficients are constant, but the intercepts vary across the firms. Then the model is stated as under,

$$
\begin{aligned}
& Y_{i t}=\alpha_{1}+\alpha_{2} D_{1}+\alpha_{3} D_{2}+\cdots+\alpha_{13} D_{12}+\beta_{1} M S_{i, t}+\beta_{2} P R O M_{i, t}+\beta_{3} R N D_{i, t-1}+ \\
& \beta_{4} L P R O D_{i, t-1}+\beta_{5} C P R O D_{i, t-1}+\beta_{6} C E_{i, t}+\beta_{7} C I_{i, t}+\beta_{8} F A T_{i, t-1}+\beta_{9} K_{i, t-1}+ \\
& \beta_{10} I M I_{i, t}+\beta_{11} N P M_{i, t}+\beta_{12} A G E_{i, t}+\beta_{13} L O C_{i, t}+\beta_{14} O W N_{i, t}+\mu_{i t}
\end{aligned}
$$

The Hausman Specification Test (1978) is applied to test the suitability of the FEM against the REM. While in FEM the intercepts are allowed to vary across the firms in order to incorporate their characteristics, in REM it is assumed that the intercept is a random draw from a large population with a constant mean value. The Hausman Specification Test examines whether there is a significant correlation between the unobserved firm-specific random effects and the regressors. If there is no such correlation, the REM is considered more appropriate. The Hausman test is based on the following test statistic.

$W=[\gamma-\lambda] \psi^{-1}[\gamma-\lambda] \sim \chi^{2}(k-1)$

Here, $\gamma$ and $\lambda$ stand for the vector of estimated coefficients of the FEM and REM respectively, $\psi$ is the variance of difference in $\gamma$ and $\lambda$ and $k$ is the number of explanatory variables. If the null hypothesis is not rejected, the REM is preferred to the FEM.

Next, a choice needs to be made between the pooled regression model and the REM. This is done to confirm the assumption of randomness. The Breusch-Pagan Lagrange Multiplier Test (1980) is applied. The Breusch-Pagan Lagrange Multiplier Test validates the REM based on the following hypotheses:

$H_{0}: \sigma_{\mu}^{2}=0$

$H_{1}: \sigma_{\mu}^{2} \neq 0$

The test uses the following test-statistic

$L M=\frac{n T}{2(n-1)}\left[\frac{\sum n \bar{\varepsilon}_{t}^{2}}{\sum \sum \varepsilon_{i t}^{2}}-1\right]^{2} \sim \chi^{2}$

Here, $T$ is the number of time periods; $n$ is the number of firms. If he computed $\chi^{2}$ is less than the critical value, that is, if the null hypothesis is not rejected, the pooled regression model is appropriate. Only if, the value of $\chi^{2}$ exceeds the critical value, the null hypothesis will be rejected in favour of the REM.

Finally, the Levin-Lin-Chu panel data unit root test is carried out to examine if the dataset used for regression analysis suffers from the problem of non-stationary, and it is found that the panels are stationary. The dataset is free from the presence of unit roots. 
Sanchita Ghosh CHOWDHURY \& Suhita CHATTERJEE

\section{Empirical Findings and Discussions}

Table 4 shows the summary statistics for the variables included in the panel data regression. The summary statistics indicate that the data does not suffer much with the problem of outliers and is strongly balanced.

\section{Table 4. Summary statistics}

\begin{tabular}{cccccc}
\hline Variable & Obs. & Mean Std. & Dev. & Min & Max \\
\hline Growth & 216 & 0.15 & 0.61 & -1.70 & 8.07 \\
\hline LPROD & 216 & 22.10 & 15.65 & 0.13 & 73.14 \\
\hline CPROD & 216 & 80.43 & 116.48 & 0.00 & 734.43 \\
\hline Cl & 216 & 1.59 & 4.61 & 0.03 & 53.28 \\
\hline KOI & 210 & 0.01 & 0.01 & 0.00 & 0.05 \\
\hline PROM & 216 & 0.08 & 0.68 & 0.00 & 10.06 \\
\hline RND & 197 & 0.01 & 0.01 & 0.00 & 0.05 \\
\hline IMI & 213 & 6.72 & 3.41 & -2.30 & 11.42 \\
\hline CE & 216 & 0.15 & 0.47 & -4.02 & 2.83 \\
\hline FAT & 216 & 7.09 & 6.10 & 0.00 & 40.79 \\
\hline NPM & 216 & 0.69 & 11.71 & -83.10 & 17.14 \\
\hline Age & 216 & 3.34 & 0.58 & 1.10 & 4.26 \\
\hline Size & 216 & 9.94 & 1.95 & 5.08 & 13.38 \\
\hline MS & 216 & 0.06 & 0.07 & 0.00 & 0.26 \\
\hline ROE & 216 & 0.01 & 1.32 & -11.98 & 1.12 \\
\hline
\end{tabular}

Note: Neg. $=$ Negligible $(<0.005)$

Additionally, the variables do not suffer from severe multicollinearity as the variable inflation factors are considerably low. Therefore, there is very little chance of the individual coefficients to be misleading. Table 5 shows the individual VIFs.

Table 5. Variance Inflation Factors (VIFs)

\begin{tabular}{lcc}
\hline Variable & VIF & $1 /$ VIF \\
\hline LPROD & 6.75 & 0.148101 \\
\hline IMI & 4.68 & 0.21362 \\
\hline MS & 4.07 & 0.245892 \\
\hline Age & 3.97 & 0.251717 \\
\hline Location & 2.56 & 0.39088 \\
\hline Ownership & 2.36 & 0.424283 \\
\hline NPM & 2.35 & 0.425443 \\
\hline RNDL & 2.34 & 0.426679 \\
\hline Cl & 2.26 & 0.442102 \\
\hline KOIL & 1.99 & 0.502251 \\
\hline PROM & 1.83 & 0.547066 \\
\hline CPROD & 1.77 & 0.563521 \\
\hline FAT & 1.64 & 0.610935 \\
\hline CE & 1.1 & 0.905323 \\
\hline Mean VIF & 2.83 & \\
\hline
\end{tabular}


Equation (9) is estimated using the Random Effects Model (REM), and the estimation results showed that the model had high predictability, and a significant $\chi 2$ was obtained. Then equation (10) is estimated using the Fixed Effects Model (FEM). This model also demonstrates good predictability and gives a significant F-statistic. Both models return several statistically significant estimators as well as some estimators that are not statistically significant. As both models show good explanatory power and return a significant test statistic, a choice between them becomes necessary. The Hausman test is then applied to justify the choice of one model over the other. The Hausman test assumes the null hypothesis that the difference in coefficients is not systematic and returns the following results (Table 6).

\section{Table 6: Results of the Hausman Test}

HO: Difference in coefficients not systematic

\begin{tabular}{ll}
\hline Chi2(17) & 19.06 \\
\hline Prob. $>$ chi 2 & 0.3250
\end{tabular}

The results clearly indicate that the null hypothesis cannot be rejected and that the difference in the coefficients may not be systematic. Therefore, the REM is more appropriate than the FEM.

After the REM has been confirmed, it is now necessary to see whether a pooled regression could be preferred over the REM. In order to make this choice, the Breusch-Pagan Lagrange Multiplier Test is applied. The Breusch-Pagan Lagrange Multiplier Test yields the following result (Table 7).

\section{Table 7. Results of Breusch-Pagan Lagrange Multiplier Test}

\begin{tabular}{lc}
\hline HO: Var. $(\mathrm{u})=0$, when Growth [Company, $\mathrm{t}]=\mathrm{Xb}+\mathrm{u}[$ Company $]+\mathrm{e}[$ Company, $\mathrm{t}]$ \\
\hline Chibar2(01) & 0.00 \\
\hline Prob $>$ chibar 2 & 1.0000 \\
\hline
\end{tabular}

The results clearly indicate that the assumption of randomness cannot be continued as the null hypothesis cannot be rejected. Therefore, the results indicate that a pooled regression will be a more appropriate choice over the Random Effects Model. This also justifies the fact that the differences across firms are not random but are impacted by external time-invariant factors like industrial policies.

Therefore, a pooled regression is then estimated, and Table 8 summarises the regression results. It is observed that the F-statistic is statistically significant, and the value of the adjusted $\mathrm{R}$ square is moderately high. Hence the estimated model is statistically significant with good explanatory power.

Further, the Levin-Lin-Chu unit root test was carried out, which confirmed that the panels are stationary and free from the presence of unit roots. 


\section{Table 8. Regression Results of Pooled OLS}

\begin{tabular}{lcc}
\hline Independent Variables & Coefficient & t- statistic \\
\hline LPROD & -0.0060 & $-2.21^{* *}$ \\
\hline CPROD & -0.0004 & $-2.36^{* *}$ \\
\hline Cl & 0.0013 & 0.11 \\
\hline KOI & 1.2884 & 0.87 \\
\hline PROM & -2.7927 & $-2.27^{* *}$ \\
\hline RND & 0.7326 & 0.19 \\
\hline IMI & 0.0230 & $2.29^{* *}$ \\
\hline CE & 0.0873 & 1.04 \\
\hline FAT & -0.0091 & $-3.14^{*}$ \\
\hline NPM & 0.0111 & $3.94^{*}$ \\
\hline Age & -0.1216 & $-2.38^{* *}$ \\
\hline MS & -0.2357 & -0.64 \\
\hline LOC & -0.0693 & -1.2 \\
\hline OWN & -0.0606 & \\
\hline R square & & 0.33 \\
\hline F( 14, 175) & $6.17^{*}$ & \\
\hline Number of Observations & 190 & \\
\hline
\end{tabular}

Notes: (i) the t-statistics are computed using robust standard error; (ii) * statistically significant at $1 \%$ level of significance; (iii) ** statistically significant at $5 \%$ level of significance; (iv) *** statistically significant at $10 \%$ level of significance

Out of all the determinants of growth, LPROD, CPROD, PROM, IMI, FAT, NPM and Age are significant. Of these significant variables, PROM represents conduct, and the others reflect performance. All these variables, except PROM, are impacted by industrial policies. This brings out the significance of industrial policies in their way of impacting automobile industry growth in India. The labour productivity measured by the variable LPROD as sales per unit of labour brings out the importance of human capital efficiency in the growth of the automobile industry in India. Increase in human capital efficiency comes because of rigorous training and development of employees together with the permanency of employment for the sake of motivation and loyalty as well as better wages. The industrial policies of the government are consistent with this effort. Various policies regarding technical and organised skill development near industrial hubs in India are already in place, and the government has an aim to achieve a higher level of skill amongst the youth in the coming years to fight the current rate of unemployment induced poverty. "The India Skills Report, 2014" 49, a report by People Strong, Confederation of Indian Industries and Wheebox, have shown that there is a huge skill gap in almost all the developing sectors of the Indian economy, including the automobile sector, which needs to be immediately addressed. The volume of capital employed that determines the value of CPROD is likely to be impacted by policies on capacity expansion and foreign direct investment. It can also be impacted by policies on tax structure, which is based on the capital structure of the firm. The import intensity measured by IMI is also a variable that is strongly impacted by industrial policies. Policies regarding custom 
duties and import regulations will impact this determinant. The FERA regulations, which put pressure on imports as did the policies regarding fuel prices. Policies for the encouragement of imports can lead to growth in the industry. The FAT is also impacted by policies like privatisation and globalisation policies, which affect the expenditure on fixed assets and thereby promote growth. The environmental norms and the budgetary and infrastructural supports all impact the asset performance of the firms and in turn their growth. The long time needed for the capital investments to break even and start generating income impacts the ratio. Another significant predictor of growth is the net profit margin, NPM, which reflects the performance of most of the other significant predictor variables. A firm that employs capital productively over a period has a trained and skilled labour force and imports current technology is expected to show significant profitability and verifiable growth, thus contributing to the growth and development of the industry. Figure 1 below gives the behaviour of the significant variable over the period under analysis. The figure clearly shows the similarity in the behaviour of the firms and hence justifies the significance.

The relationships of all the determinants with growth are as expected, except for the location dummy. The negative relationships are more indicative of the pioneering nature of the industry. When an industry is in its initial stages of development, the expenses increase at a higher rate than its turnover thus leading to a negative relationship between growth and the expenditure related performance ratios. The location dummy shows an unexpected negative relationship with growth, implying that the presence of a firm in one of the three clusters in the country is deterrent to its growth. One possible explanation can be that presence in these clusters together with giving the benefit of easy availability of inputs also has the disadvantage of increased input and manpower costs which is deterrent to profitability and hence to growth.

The variables which are not statistically significant include $\mathrm{Cl}, \mathrm{KOI}, \mathrm{RND}, \mathrm{C} . \mathrm{E} ., \mathrm{MS}, \mathrm{LOC}$ and OWN. The variables $\mathrm{Cl}$ and C.E. representing the capital-labour ratio and the change in capital employed respectively, refer to the capital-intensive nature of the industry. As the industry was already capital intensive since the liberalisation period of the 1980s and have remained so, therefore, these variables may not have shown any significant contribution to the growth of the industry for the period under analysis. Knowledge outsourcing intensity, $\mathrm{KOI}$, is an important contributor to growth but has picked up pace only after the encouragement given by the Auto Policy of 2002 and other industrial policies for the automobile sector in India after the Auto Policy of 2002. Hence, the impact of the variable has been dampened by the period taken under the current analysis. An analysis with a shorter period post2005 may have given a significant impact of the variable on automobile industry growth. Market share (MS) is another predictor that demonstrates no statistical significance. 



Figure 1. Behaviour of Significant Predictor Variables over Time 

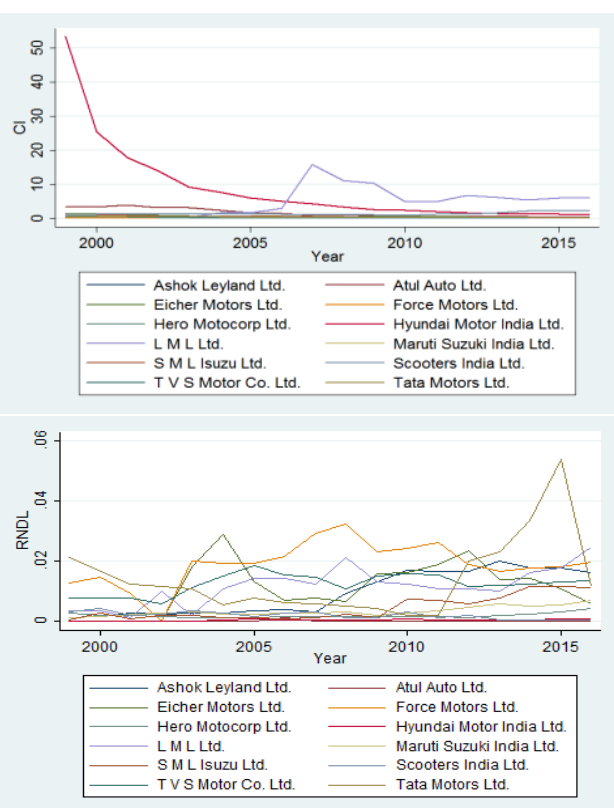
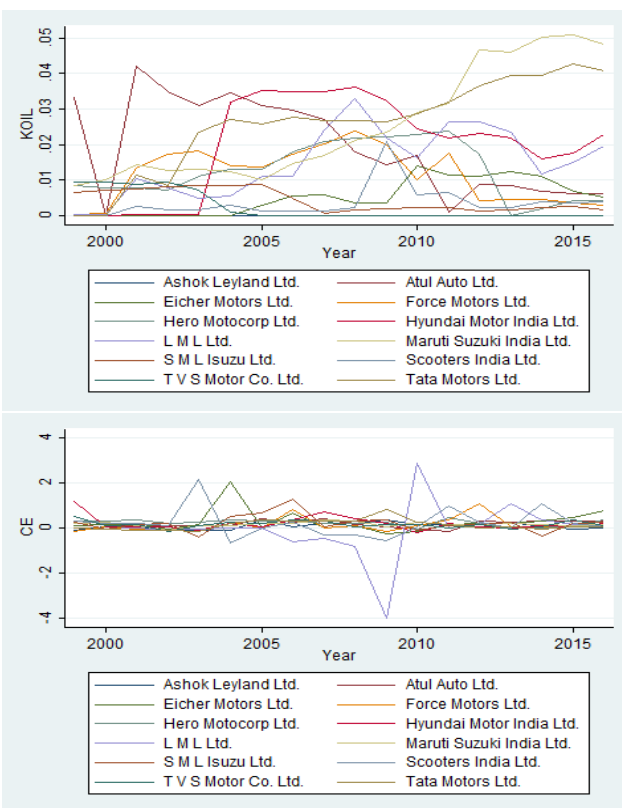

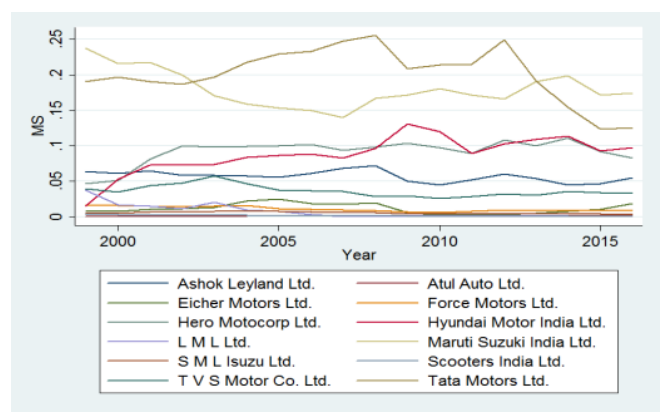

Figure 2. Behaviour of Non-Significant Variables over Time

As shown in Table 1, this behaviour is not entirely unexpected. As all firms in the industry demonstrate growth, their market shares cannot be expected to rise at the same time. The larger firms have shown a fall in market share, whereas some smaller firms have grown in market share. Several new competitors have also entered the market. Thus, the market share is only indicative of the changing nature of oligopoly from the leadership model to the contestable market model but is unable to significantly predict growth. However, research and development intensity, measured by RND, is influenced by industrial policies. The weighted tax deductions given for research and development initiatives have led to an increase in the activity post-2005. However, the low intensity of the research and development activity and the fact that research and development expenses started to pick up pace only post 
2005, maybe a justifiable cause for the variable to have no significant impact on firm growth. Again, the lack of significance of the dummy variables location (LOC) and ownership (OWN) signify that the presence of a manufacturing unit in one of the clusters or the presence of foreign involvement or joint ventures does not impact the growth of the firm. Since there are no separate industrial policies for such firms, the impact of industrial policies on such determinants is also negligible. Figure 2 shows the behaviour of these variables over time. The randomness in the behaviour of the firms is again indicative of their poor impact of growth.

\section{Conclusion}

Thus, on the basis of the above empirical analysis, it may be concluded that the determinants labour and capital productivity, promotional measures, import intensity, fixed asset turnover, net profit margin and age of the firm are significant determinants of automobile industry growth in India. Of these significant variables, PROM represents conduct, and the others reflect performance. All these variables, except PROM, are impacted by industrial policies. This brings out the significance of industrial policies in their way of impacting automobile industry growth in India. The Indian automobile industry requires a long-term stable policy environment for having sustainable growth and government should henceforth provide such a policy environment (James, 2019). Favourable industrial policies will have a positive impact, whereas unfavourable policies will deter growth by impacting the conduct and performance of firms in the industry. Favourable policies which impact the level of capital employed and its competence supports the building up efficient human capital through the development of technical and automotive skills and allows favourable technology and component imports without restricting the profitability of the business will help to promote significant growth in the automobile industry in India. Therefore, it is necessary to create a favourable economic climate by carefully structuring the industrial policies with respect to the industry.

\section{References}

Badri Narayan, G. \& Vashisht, P. (2008). Determinants of Competitiveness of the Indian Auto Industry, Indian Council For Research On International Economic Relations Working paper (201). Retrieved from http://icrier.org/pdf/Working\%20Paper\%20201.pdf

Bain, S. J. (1951). Relation of Profit Rate to Industry Concentration: American Manufacturing, 1936-40. Quarterly Journal of Economics, 68, 293-324. https://doi.org/10.2307/1882217

Barthwal, R. R. (1977). The Determinants of Profitability in Indian Textile Industry. The Indian Journal of Economics, 57, 429-440.

Barthwal, R.R. (2010). Industrial Economics: An Introductory Textbook, New Age International Publishers.

Bhasker, V. (2013). Foreign Direct Investment (FDI) in Indian Automobile Industry: Impact on Employment Generation. Research Journal of Management Sciences, 2(2), 14-22. 
Burange, L. G., \& Yamini, S. (2008, February). Competitiveness of Firms in Indian Automobile Industry. In International Conference on Transportation System Studies, Department of Economics, University of Mumbai. Retrieved from https://www.researchgate.net/publication/280727279 Competitiveness of Firms in India n Automobile Industry

Chadha, S.K. and Kapoor, D. (2010). A Study on Knowledge Management Practices of Auto Component Manufacturing Companies in Ludhiana City. The IUP Journal of Knowledge Management, 8(1\&2), 68-76.

Chattopadhyay, U. (2013). Demystifying the Growth Story of Indian Passenger Car Industry. International Journal of Trade, Economics and Finance, 4(3), 111-118. https://doi.org/10.7763/IJTEF.2013.V4.269

Chaudhuri, A., Koudal, P., \& Seshadri, S. (2010). Productivity and capital investments: An empirical study of three manufacturing industries in India. IIMB Management Review, 22, 6579. https://doi.org/10.1016/j.iimb.2010.04.012

Corvers, F. (1997). The impact of human capital on labour productivity in manufacturing sectors of the European Union. Applied Economics, 29(8), 975-987. https://doi.org/10.1080/000368497326372

Das, S \& Das, P. (2012). Role of Research and Development in Indian Automobile Industry, Asian-African Journal of Economics and Econometrics, 12(1), 79-87.

Dasgupta, R. (1986) Liberalisation of Automobile Industry Policy and Demand for Commercial Vehicles. Economic and Political Weekly, 21(8), M2-M8.

Dogan, B., Albeni, M., Baydar, V. \& Omer, A. (2016). A Research on the Performance and Characteristics of the Firms in Turkish Manufacturing Industry, Eurasian Journal of Business and Economics, 9(17), 67-86. https://doi.org/10.17015/ejbe.2016.017.05

Edwards, S., Allen, A. \& Shaik, S. (2006). Market Structure Conduct Performance (SCP) Hypothesis Revisited using Stochastic Frontier Efficiency Analysis. In 2006 Annual Meeting, July 23-26, Long Beach, CA (No. 21350). American Agricultural Economics Association Retrieved from http://ageconsearch.umn.edu/bitstream/21350/1/sp06ed01.pdf.

Gale, T. B. (1972). Market Share and Rate of Return. Review of Economics \& Statistics, 54(4), 412-423. https://doi.org/10.2307/1924568

Garg, R. \& Singh, T. (2005). Status of Socio-technical Change in Indian Automobile Industry - A Longitudinal Study. Global Journal of Flexible Systems Management, 6(3/4), 25-37.

Hall, M. \& Weiss, L. (1967). Firm Size and Profitability. Review of Economics and Statistics, 49, 319-331. https://doi.org/10.2307/1926642

Humphrey, J. \& Memedovic, O. (2003). The Global Automotive Industry Value Chain: What Prospects for Upgrading by Developing Countries. Sectoral Studies Series, United Nations Industrial Development Organization. https://doi.org/10.2139/ssrn.424560

James, N. (2019, December 26). Automobile: Firmly in the grip of a slowdown, The Hindu Business Line. Retrieved from https://www.thehindubusinessline.com/companies/firmly-inthe-grip-of-a-slowdown/article30396906.ece

Kathuria, S. (1987). Commercial Vehicles Industry in India: A Case History, 1928-1987. Economic and Political Weekly, 22(42/43), 1809-1813+1815-1823

Kaul, V. (2016, January 8). Eight Economic Indicators Which Tell Us that the Indian Economy is Not Doing Well. Equity Master. Retrieved from 
https://www.equitymaster.com/diary/detail.asp?date=01/08/2016\&story=1\&title=EightEconomic-Indicators-which-Tell-Us-that-the-Indian-Economy-is-Not-Doing-Well

Kim, Y. C. \& McElreath, R. (2001). Managing operating exposure: A case study of the automobile industry. Multinational Business Review, 9(1), 21-26.

Kumar, N. \& Kaur, K. (2014). Some Aspects of Indian Automobile Industry- An Analysis. Social Vision, 1(3), 245-252.

Lall, S. (2003). Reinventing industrial strategy: The role of government policy in building industrial competitiveness. QEH Working Paper Series (111), University of Oxford. Retrieved from https://pdfs.semanticscholar.org/1bac/21f4e522ac957e935328a875d8963927b217.pdf Lee, H. \& Anderson, B. (2006). Automobile Industry in China and India: Backgrounds, Trends and Perspectives. The Business Review, Cambridge, 6(1), 308- 314.

M. B. \& Kang, J. (2008). How to measure company productivity using value-added: A focus on Pohang Steel (POSCO). Asia Pacific Journal of Management, 25(2), 209-224. https://doi.org/10.1007/s10490-007-9081-0

Menon, B. \& Raj, J. (2012). Model Development and Validation for Studying Consumer Preferences of Car Owners. International Journal of Marketing and Technology, 2(5), 148-173.

Miglani, S. (2019). The Growth of the Indian Automobile Industry: Analysis of the Roles of Government Policy and Other Enabling Factors, In Innovation, Economic Development, and Intellectual Property in India and China, pp 439-463. (pp. 439-463). Springer, Singapore. https://doi.org/10.1007/978-981-13-8102-7 19

Mishra, P. (2008). Concentration-Markup Relationship in Indian Manufacturing Sector. Economic and Political Weekly, 43(38), 75-80.

Mogos, S., Davis, A. \& Baptista, R. (2015). Defining High Growth Firms: Sustainable Growth, Volatility, and Survival. DRUID15, Rome June 15,17. Retrieved from http://druid8.sit.aau.dk/acc papers/rpq1k6cpebbhti9vh29xudqp3juy.pdf

Mudkanna, R. \& Losarwar, S.G. (2014). Training Practices Followed by Automobile Industries. Asian Journal of Management Sciences, 2(5), 18-20.

Mukherjee, A. (2000). The Indian Automobile Industry: Speeding into the Future? Actes du GERPISA, 28, 35-48.

Mukherjee, A., \& Sastry, T. (1996). Automotive Industry in Emerging Economies: A Comparison of South Korea, Brazil, China and India. Economic and Political Weekly, 31(48), M75-M78.

Nag, B. (2011). Trade Liberalisation and International Production Networks in Asia: Experience of Indian Automotive Sector (pp. 100-130). United Nations Economic and Social Commission for Asia and the Pacific (ESCAP). Retrieved from http://artnet.unescap.org/tid/projects/tiri nag.pdf

Nag, B., Banerjee, S., \& Chatterjee, R. (2007). Changing Features of the Automobile Industry in Asia: Comparison of Production, Trade and Market Structure in Selected Countries (No. 3707). Asia-Pacific Research and Training Network on Trade (ARTNeT). Retrieved from http://www.unescap.org/sites/default/files/AWP\%20No.\%2037.pdf

Narayanan, K. (1998) Technology acquisition, de-regulation and competitiveness: a study of Indian automobile industry. Research Policy, 27, 215-228. https://doi.org/10.1016/S0048$\underline{7333(98) 00037-7}$ 
Narayanan, K. (2001). Liberalisation and The Differential Conduct and Performance of Firms: A Study of the Indian Automobile Sector. Discussion Paper Series A No.414, retrieved from http://hermes-ir.lib.hit-u.ac.jp/rs/bitstream/10086/13838/1/DP414.pdf

Nauhria, Y., Pandey, S., \& Kulkarni, M.S. (2011), Competitive Priorities for Indian Car Manufacturing Industry (2011-2020) for Global Competitiveness. Global Journal of Flexible Systems Management, 12(3/4), 9-20. https://doi.org/10.1007/BF03396603

People Strong, Confederation of Indian Industries \& Wheebox. (2014). The India Skills Report, 2014. Retrieved from https://wheebox.com/logo/FullVersion.pdf

Petersen, D. \& Ahmad, N. (2007). High-Growth Enterprises and Gazelles -Preliminary and Summary Sensitivity Analysis. OECD-FORA, Paris. Retrieved from https://studylib.net/doc/11556607/high-growth-enterprises-and-gazelles-\%E2\%80\%93-

preliminary-and-su

Piplai, T. (2001). Automobile Industry: Shifting Strategic Focus. Economic and Political Weekly, 36(30), 2892-2897.

Ranawat, M. \& Tiwari, R. (2009). Influence of Government Policies on Industry Development: The Case of India's Automotive Industry. Technology and Innovation Management (University of Hamburg) Working Paper, (57). https://doi.org/10.2139/ssrn.1583449

Rao, C. B. (1993). Structural Configuration and Strategic Investments: Indian Automobile Industry. Economic and Political Weekly, 28(8/9), M21-M25, M28-M32.

Ray, S. (2012). Economic Performance of Indian Automobile Industry: An Econometric Appraisal. Business Intelligence Journal, 5(1), 151-162.

Richet, X. \& Ruet, J. (2008). The Chinese and Indian Automobile Industry in Perspective: Technology Appropriation, Catching-up and Development. Transition Studies Review, 15(3), 447-465. https://doi.org/10.1007/s11300-008-0019-0

Robert D., Buzzell, R. D., Gale Bradley T. \& Sultan, G.M. (1975). Market Share-a Key to Profitability. Harvard Business Review, January, 23-41. Retrieved from https://hbr.org/1975/01/market-share-a-key-to-profitability

Sahoo, D. \& Mishra, P. (2012). Structure, Conduct and Performance of Indian Banking Sector. Review of Economic Perspectives, 12(4), 235-264. https://doi.org/10.2478/v10135-012-0011$\underline{9}$

Samuel, J., \& Smith, D. (1968). Profits, Variability of Profits and Firm Size. Economica, 35, 127139. https://doi.org/10.2307/2552126

Saripalle, M. (2012). Learning and Capability Acquisition: A Case Study of the Indian Automobile Industry. Retrieved from http://citeseerx.ist.psu.edu/viewdoc/download?doi=10.1.1.390.3954\&rep=rep1\&type=pdf

Schwartzman, D. (1959). Effect of Monopoly on Price. Journal of Political Economy, 167, 352362. https://doi.org/10.1086/258195

Singh, A, \& Whittington, G. (1968). Growth, Profitability and Valuation. D. A. E. Occasional Paper No. 7, Cambridge University Press.

Vikkraman, P. \& Varadharajan, P. (2009). A Study on Risk \& Return analysis of Automobile industry in India (2004-2007). Journal of Contemporary Research in Management, 35-40.

Yilmaz, I. \& Acar, G. (2018). The Effects of Intellectual Capital on Financial Performance and Market Value: Evidence from Turkey. Eurasian Journal of Business and Economics, 11(21), 117 133. https://doi.org/10.17015/ejbe.2018.021.07 